\title{
A hospital based prospective study of vitamin D deficiency in a selected group of apparently healthy children one to five years of age
}

\author{
Prabhjot Kaur Dhillon ${ }^{1}$, *Gursharn Singh Narang ${ }^{2}$, Sunita Arora ${ }^{2}$, Sahiba Kukreja ${ }^{3}$
}

Sri Lanka Journal of Child Health, 2015; 44(3): 158-162

\begin{abstract}
Objective: To study the presence of vitamin D deficiency in a selected group of apparently healthy children 1-5 years of age
\end{abstract}

Method: A hospital based prospective crosssectional study was carried out at the Sri Guru Ramdas Institute of Medical Sciences and Research (SGRDIMSR), Amritsar on a selected group of apparently healthy children of age group 1 to 5 years, attending the paediatrics outpatient department for minor ailments or immunization from December 2012 to June 2014. Venous samples from these children were collected in two separate red topped vials (with clot activator), one for vitamin $\mathrm{D}$ and the other for alkaline phosphatase and calcium. These vials were sent to the Biochemistry Department of SGRDIMSR hospital. Data so obtained was statistically analysed.

Results: Out of a total of 100 apparently healthy children, 78 were found to be deficient in Vitamin D. Vitamin D levels were tested by the Direct ELISA method. Vitamin D deficiency was found most commonly in the age group $4-5$ years. Gender wise, $79.4 \%$ of boys and $75.7 \%$ of girls were found to be vitamin $\mathrm{D}$ deficient. Of breast fed children $76.6 \%$ were found deficient in vitamin $\mathrm{D}$. Of the children who spent less than 30 minutes per day in the sun $73.1 \%$ were vitamin D deficient. Most $(80 \%)$ cases of vitamin D deficiency were found in the upper middle class. Urban population was found to be more deficient in vitamin $D$ as compared to rural. Fifty four percent of the children with vitamin $\mathrm{D}$ deficiency were of wheatish complexion. Dietary insufficiency was found in $67 \%$ of the children, of whom $82 \%$ were found to be vitamin $\mathrm{D}$ deficient. Clinical features of vitamin D deficiency found in our study were frontal bossing, parietal bone prominences, widening of wrist epiphyses and pot belly.

1'Junior Resident, ${ }^{2}$ Professor (Paediatrics),
${ }^{3}$ Professor (Biochemistry), Sri Guru Ram Das
Institute of Medical Sciences and Research,
Amritsar, India
*Correspondence: gsnarang321@gmail.com

(Received on 27 August 2014: Accepted after revision on 24 October 2014)
Conclusion: In the selected group of apparently healthy children 1-5 years of age vitamin D deficiency was found in $78 \%$.

(Key words: vitamin D deficiency; children; India)

\section{Introduction}

In India vitamin D deficiency has been reported to be present in the majority of children in spite of the wide availability of sunlight. Mild or subclinical vitamin $\mathrm{D}$ deficiency escapes diagnosis because of its nonspecific symptomatology ${ }^{1}$.

\section{Objective}

To study the presence of vitamin D deficiency in a selected group of apparently healthy children 1-5 years of age

\section{Method}

A hospital based prospective cross-sectional study was conducted in the Department of Paediatrics in collaboration with the Department of Biochemistry at Sri Guru Ram Das Institute of Medical Sciences and Research Centre, Amritsar from December 2012 to June 2014 on children of age group 1 - 5 years attending the paediatric outpatient department for minor ailments or immunization or admitted to the paediatric ward for minor ailments. Children on steroids, children suffering from bronchial asthma, chronic renal disease, chronic / acute liver disease and acutely ill children were excluded from the study. Of the eligible children, only those whose parents could afford the cost of the investigations were included in the study.

Venous samples from these apparently healthy children with normal anthropometric parameters were collected under aseptic conditions in two separate red topped vials (with clot activator) and sent for estimation of serum $25 \mathrm{OH}$ vitamin D, serum calcium and alkaline phosphatase levels. Direct ELISA with immunodiagnostix kit was used for estimation of $25 \mathrm{OH}$ vitamin D levels in serum. Data so obtained was statistically analyzed by Microsoft SPSS, Version 18.0. For inferential analysis, Chi-square and independent t-test were done at the level of significance $\mathrm{p}=0.05$ (Confidence interval $=95 \%$ ). The normal value of vitamin D was taken as more than $30 \mathrm{ng} / \mathrm{ml}$, vitamin 
A hospital based prospective study of vitamin D deficiency in a selected group of apparently healthy children one to five years of age Sri Lanka Journal of Child Health, 2015; 44(3): 158-162

D insufficiency as $20-30 \mathrm{ng} / \mathrm{ml}$ and vitamin D deficiency as less than $20 \mathrm{ng} / \mathrm{ml}^{2}$.

\section{Results}

Out of the 100 apparently healthy children included in the study, 78 were found to be deficient in Vitamin D (levels $<20 \mathrm{ng} / \mathrm{ml})$. Vitamin D deficiency was found in $90 \%$ of children $4-5$ years old, $86.7 \%$ of children $2-3$ years old, $72.7 \%$ of children $1-2$ years old, $66.7 \%$ of children $3-4$ years old and 57\% infants (Figure 1).

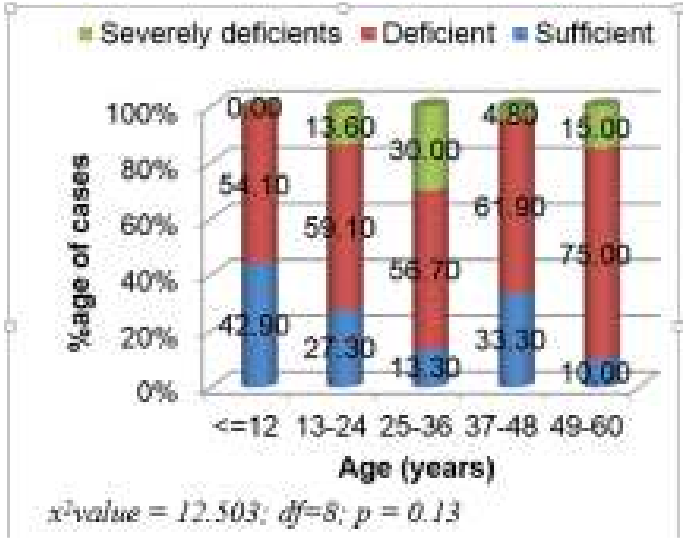

Figure 1: Association of age with vitamin D deficiency
When compared with children with normal vitamin D levels, no significant difference was found in age distribution of both groups $(p=0.13)$.

Dietary insufficiency was found in $67 \%$ of the children, $82 \%$ of whom were found to be vitamin D deficient (Figure 1). The results were statistically significant $(\mathrm{p}=0.03)$.

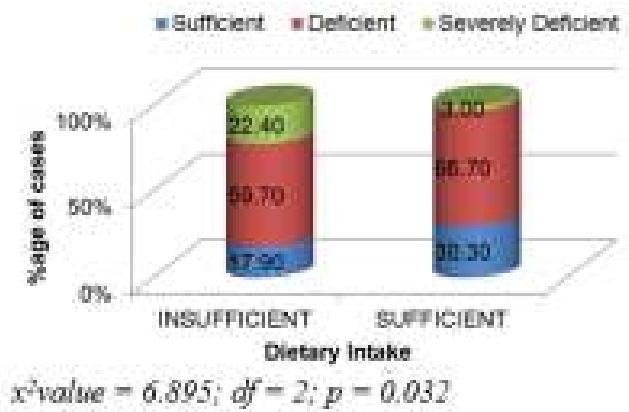

Figure 2: Association of dietary intake with vitamin $D$ deficiency

Out of a total of 63 boys $50(79.4 \%)$ were vitamin $\mathrm{D}$ deficient and 28 girls out of $37(75.7 \%)$ were vitamin $\mathrm{D}$ deficient (Table 1$)$. The difference was not statistically significant $(\mathrm{p}=0.902)$. Out of 90 breast fed children $69(76.6 \%)$ were found to be deficient in Vitamin D (Table 2). The results were not statistically significant $(\mathrm{p}=0.08)$.

Table 1: Association of gender with vitamin D deficiency

\begin{tabular}{|l|c|c|c|c|}
\hline \multicolumn{1}{|c|}{ Sex } & Sufficient & Deficient & Severely deficient & Total \\
\hline Male & $13(20.6 \%)$ & $40(63.5 \%)$ & $10(15.9 \%)$ & $63(100 \%)$ \\
\hline Female & $09(24.3 \%)$ & $22(59.5 \%)$ & $06(16.2 \%)$ & $37(100 \%)$ \\
\hline Total & $22(22.0 \%)$ & $62(62.0 \%)$ & $16(16.0 \%)$ & $100(100 \%)$ \\
\hline
\end{tabular}

$x^{2}$ value $=0.207 ; d f=2 ; p=0.902$

Table 2: Association of breast feeding with vitamin D deficiency

\begin{tabular}{|c|c|c|c|c|}
\hline Breast feeding & Sufficient & Deficient & Severely Deficient & Total \\
\hline No & $01(10.0 \%)$ & $05(50.0 \%)$ & $04(40.0 \%)$ & $10(100 \%)$ \\
\hline Yes & $21(23.3 \%)$ & $57(63.3 \%)$ & $12(13.3 \%)$ & $90(100 \%)$ \\
\hline Total & $22(22.0 \%)$ & $62(62.0 \%)$ & $16(16.0 \%)$ & $100(100 \%)$ \\
\hline
\end{tabular}

$x^{2}$ value $=4.9 ; d f=2 ; p=0.08$

Of the children who spent less than 30 minutes per day in the sun $73.1 \%$ were vitamin $\mathrm{D}$ deficient (Figure 3). Results were not statistically significant $(\mathrm{p}=0.117)$

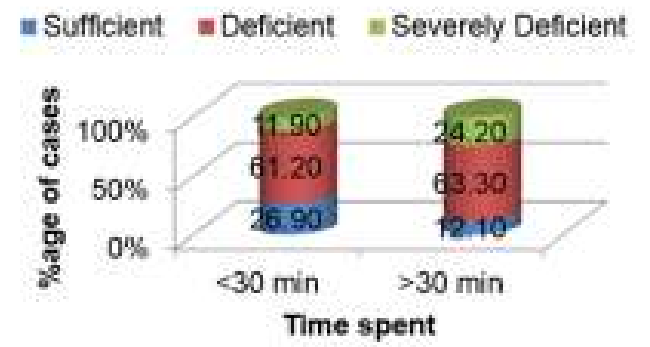

$x^{2}$ value $=4.297 ; d f=2 ; p=0.117$

Figure 3: Association of time spent in sunlight per day with vitamin $D$ deficiency 
A hospital based prospective study of vitamin D deficiency in a selected group of apparently healthy children one to five years of age Sri Lanka Journal of Child Health, 2015; 44(3): 158-162

The distribution of cases according to the socioeconomic status (Kupuswamy scale) is shown in Figure 4.

-HGH $=$ LOW $=$ LOWER MIDDLE $=$ UPPER MIDDLE

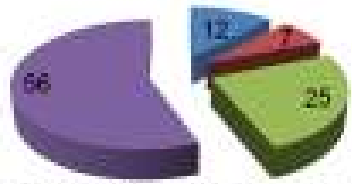

Figure 4: Distribution of cases according to socioeconomic status (Krpuswamy scale)

Most $(80 \%)$ cases of vitamin D deficiency were found in the upper middle class (Figure 5). However, this was not statistically significant $(\mathrm{p}=$ $0.575)$.

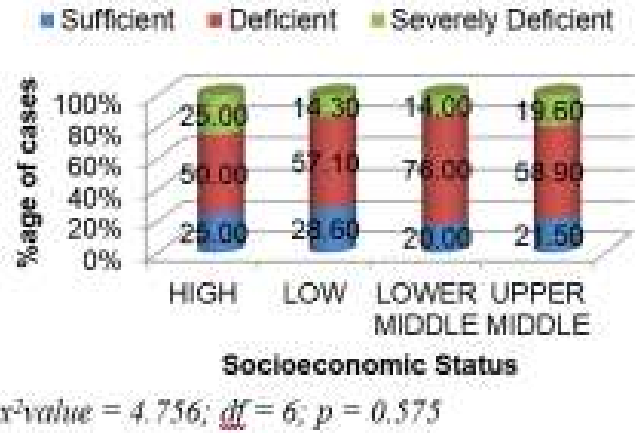

Figure 5: Association of socioeconomic status with vitamin $D$ deficiency

Urban population was found to be more deficient in vitamin $\mathrm{D}$ when compared to rural (Table 3$)$. This was not statistically significant $(\mathrm{p}=0.055)$.

Table 3: Association of background with vitamin $D$ deficiency

\begin{tabular}{|c|c|c|c|c|}
\hline Background & Sufficient & Deficient & Severely Deficient & Total \\
\hline Rural & $12(24 \%)$ & $26(52 \%)$ & $12(24 \%)$ & $50(100 \%)$ \\
\hline Urban & $10(20 \%)$ & $36(72 \%)$ & $04(08 \%)$ & $50(100 \%)$ \\
\hline Total & $22(22 \%)$ & $62(62 \%)$ & $16(16 \%)$ & $100(100 \%)$ \\
\hline
\end{tabular}

$x^{2}$ value $=5.795 ; d f=2 ; p=0.055$

Fifty four percent of the children with vitamin D deficiency were of wheatish complexion. This was not statistically significant $(\mathrm{p}=0.06)$. No child in our study deficient in vitamin D was getting vitamin D supplements. The only clinical features of vitamin D deficiency found in our study were frontal bossing, parietal bone prominences, widening of wrist epiphyses and pot belly (Figure $6)$.

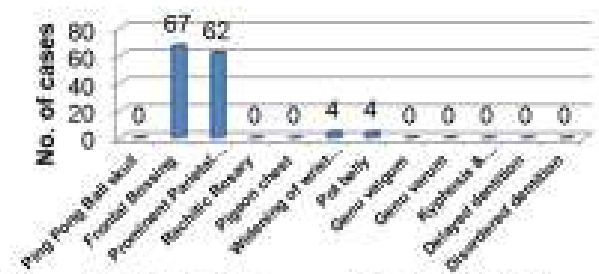

Figure 6: Clinical features of vitamin $D$ deficiency found in our study

Of the vitamin D deficient cases, $98 \%$ had normal serum calcium levels and only $2 \%$ cases had decreased serum calcium levels $(\mathrm{p}=0.73)$. Of the vitamin D deficiency cases, $2.5 \%$ showed increased levels of alkaline phosphatase (ALP) but this was statistically insignificant $(\mathrm{p}=0.23)$.

\section{Discussion}

Krieter SR et al in 2000 studied characteristics of infants and children diagnosed with nutritional rickets at two medical centres in North Carolina in the $1990 \mathrm{~s}^{3}$. The age at diagnosis was 5 to 25 months, with a median age of 15.5 months. In our study, vitamin D deficiency was found in $90 \%$ of children 4-5 years old. In 2008 Marwaha RK et al studied vitamin $\mathrm{D}$ and bone mineral density of healthy school children in northern India and found that insufficient dietary intake is associated with vitamin $\mathrm{D}$ deficiency ${ }^{2}$. In our study dietary insufficiency was found in $67 \%$ of the children, $82 \%$ of whom were found to be vitamin D deficient. A study conducted by Shin YH et al in 2013 revealed that vitamin D deficiency in children is more prevalent in the female gender ${ }^{4}$. In our study vitamin D deficiency was found equally in both sexes. In 2006, Ziegler EE et al studied vitamin $\mathrm{D}$ deficiency in breastfed infants in Iowa. Vitamin D deficiency was common among breastfed infants in Iowa ${ }^{5}$. In our study $76.6 \%$ of breast fed children were found to be deficient in Vitamin D.

Bener A et al conducted a cross-sectional study at the Primary Health Care from August 2007 to March $2008^{6}$. Lack of exposure to sunlight, outdoor activities under the sun, and physical activity and vitamin $\mathrm{D}$ intake were the main associated factors for vitamin D deficiency in the young population of Qatar. Various studies done by Sahu, Balasubramanium, Harinarayan and Goswami also revealed that vitamin $\mathrm{D}$ deficiency is more prevalent in those who have lesser exposure to sunlight $^{7-11}$. In our study, of the children who spent less than 30 minutes per day in the sun $73.1 \%$ were vitamin D deficient. A study conducted by Shin YH et al revealed that vitamin $\mathrm{D}$ deficiency in children 
A hospital based prospective study of vitamin D deficiency in a selected group of apparently healthy children one to five years of age Sri Lanka Journal of Child Health, 2015; 44(3): 158-162

is more prevalent in low socioeconomic status ${ }^{4}$. In our study, $80 \%$ cases of vitamin D deficiency were found in the upper middle class. C.V. Harinarayan in March 2008 conducted a population based study in Anthra Pradesh ${ }^{9}$. The quality of diet in the rural subjects was low in calcium and high in phytate/calcium ratio compared to that of urban diet. Hence the rural subjects were more affected. In another study done by Harinarayan, it was found that urban population was more deficient ${ }^{10}$. In our study the urban population was found to be more deficient in vitamin D when compared to rural but this difference was not statistically significant. In 2008, Rovner AJ et al studied hypovitaminosis D among healthy children in the United States and found that children with dark complexion had higher prevalence of vitamin D deficiency ${ }^{12}$. In our study $54 \%$ of the children with vitamin D deficiency were of wheatish complexion. In 2007 Ward LM et al studied vitamin D deficient rickets among children in Canada. Vitamin D-deficiency rickets was persistent among those who were breast-fed without appropriate vitamin D supplementation $^{13}$. None of the children in our study deficient in vitamin $\mathrm{D}$ were getting vitamin $\mathrm{D}$ supplements. A study done by Heaney RP in 2003 showed that there exists no relation between levels of $25(\mathrm{OH})$ vitamin $\mathrm{D}$ and serum calcium levels ${ }^{14}$. In our study, of the vitamin D deficient cases, $98 \%$ had normal serum calcium levels. A study done by Maha MMHK showed positive correlation between vitamin D deficiency and increased ALP levels ${ }^{15}$. In our study only $2.5 \%$ of the vitamin D deficiency cases had increased levels of ALP.

\section{Conclusion}

In a selected group of apparently healthy children 1-5 years of age vitamin D deficiency was found in $78 \%$.

\section{Limitation of Study}

The major limitation of this study was that only eligible children whose parents could afford the cost of investigations were included in the study.

Despite the above limitation, the finding of vitamin $\mathrm{D}$ deficiency in $78 \%$ of apparently healthy children 1-5 years old is a matter for concern and warrants further study.

\section{References}

1. Lips P. Relative value of $25(\mathrm{OH}) \mathrm{D}$ and 1 , 25(OH) D2 measurements. Journal of Bone and Mineral Research 2007; 22:1668-71. http://dx.doi.org/10.1359/jbmr.070716 PMid: 17645404
2. Marwaha RK, Sripathy G. Vitamin D \& bone mineral density of healthy school children in northern India: Indian Journal of Medical Research 2008; 127(3):239-44. PMid: 18497437

3. Kreiter SR, Schwartz RP, Kirkman HN, Charlton PA, Calikoglu AS, Davenport ML. Nutritional rickets in African American breast-fed infants. Journal of Pediatrics 2000; 137(2):153-7. http://dx.doi.org/10.1067/mpd.2000.10900 9

PMid: 10931404

4. Shin YH, Shin HJ, Lee YJ .Vitamin D status and childhood health. Korean Journal of Pediatrics 2013; 56(10):41723.

http://dx.doi.org/10.1067/mpd.2000.10900 9

PMid: 10931404

5. Ziegler EE, Hollis BW, Nelson SE, Jeter JM. Vitamin D deficiency in breastfed infants in breast fed infants in lowa. Paediatrics 2006; 118(2):603. http://dx.doi.org/10.1542/peds.2006-0108 PMid: 16882813

6. Bener A, Ali-Ali M, Hoffman GF. High prevalence of vitamin $\mathrm{D}$ deficiency in young children in a highly sunny humid country: a global health problem. Minerva Pediatrica 2009; 1:15-22.

7. Sahu M, Bhatia V, Aggarwal A, Rawat V, Saxena P, Pandey A et al. Vitamin D deficiency in rural girls and pregnant women despite abundant sunshine in northern India. Clinical Endocrinology (Oxf) 2009; 70(5):680-4.

http://dx.doi.org/10.1111/j.13652265.2008 .03360.x

PMid: 18673464

8. Balasubramanian K, Rajeswari J, Gulab, Govil YC, Agarwal AK, Kumar A. Varying role of vitamin $\mathrm{D}$ deficiency in the aetiology of rickets in young children vs. adolescents in northern India. Journal of Tropical Pediatrics 2003; 49(4):201-6. http://dx.doi.org/10.1093/tropej/49.4.201

PMid: 12929879 
A hospital based prospective study of vitamin D deficiency in a selected group of apparently healthy children one to five years of age Sri Lanka Journal of Child Health, 2015; 44(3): 158-162

9. Harinarayan CV, Ramalakshmi T, Prasad UV, Sudhakar D. Vitamin D status in Andhra Pradesh: a population based study. Indian Journal of Medical Research 2008; 127:211-8.

PMid: 18497434

10. Harinarayan CV, Ramalakshmi T, Prasad UV, Sudhakar D, Srinivasarao PV, Sarma $\mathrm{KV}$ et al. High prevalence of low dietary calcium and low vitamin D status in healthy south Indians. Asia Pacific Journal of Clinical Nutrition 2004; 13:359-64.

PMid: 15563441

11. Goswami R, Kochupillai N, Gupta N, Goswami D, Singh N, Dudha A. Presence of vitamin-D deficiency in rural north Indian village despite abundant sunshine. Journal of the Association of Physicians of India 2008; 56:755-7.

PMid: 15563441

12. Rovner AJ, O'Brien KO. Hypovitaminosis D among healthy children in the United States. Archives of Pediatrics and Adolescent Medicine 2008; 162(6):513-9. http://dx.doi.org/10.1001/archpedi.162.6.5 13

PMid: 18524740
13. Ward LM, Gaboury I, Ladhani M, Zlotkin S. Vitamin D-deficiency rickets among children in Canada. Canadian Medical Association Journal 2007; 177(2):161-6. http://dx.doi.org/10.1503/cmaj.061377 PMid: 17600035 PMCid: PMC1913133

14. Heaney RP, Dowell MS, Hale CA, Bendich A. Calcium absorption varies within the reference range for serum 25hydroxyvitamin D. Journal of the American College of Nutrition 2003; 22:142-6.

http://dx.doi.org/10.1080/07315724.2003. 10719287

PMid: 12672710

15. Mansour MMHK, Alhadidi KM. Vitamin $\mathrm{D}$ deficiency in children living in Jeddah, Saudi Arabia. Indian Journal of Endocrinology and Metabolism 2012;16(2):263-9

http://dx.doi.org/10.4103/22308210.93746

PMid: 22470865 PMCid: PMC3313746 